This is the final peer-reviewed accepted manuscript of:

"Influence of the synthetic procedures on the structural and optical properties of mixed halides $(\mathrm{Br}, \mathrm{I})$ perovskite films"

P. Fedelia, F. Gazza, D. Calestani, P. Ferro, T. Besagni, G. Calestani, E. Marchi, P. Ceroni, R. Mosca

J. Phys. Chem. C 2015, 119, 21304-21313

The final published version is available online at:

https://doi.org/10.1021/acs.jpcc.5b03923

Rights / License:

The terms and conditions for the reuse of this version of the manuscript are specified in the publishing policy. For all terms of use and more information see the publisher's website.

This item was downloaded from IRIS Università di Bologna (https://cris.unibo.it/)

When citing, please refer to the published version. 


\title{
Influence of the Synthetic Procedures on the Structural and Optical Properties of Mixed Halides (Br, I) Perovskite Films
}

\author{
Paolo Fedelii ${ }^{\mathrm{a}}$, Francesco Gazza ${ }^{\mathrm{a}, \mathrm{b}}$, Davide Calestani ${ }^{\mathrm{a}}$, Patrizia Ferro ${ }^{\mathrm{a}}$, Tullo Besagni ${ }^{\mathrm{a}}$, Andrea \\ Zappettini $^{\mathrm{a}}$, Gianluca Calestani ${ }^{\mathrm{a}, \mathrm{c}}$, Enrico Marchi ${ }^{\mathrm{b}}$, Paola Ceroni $^{\mathrm{b}}$, Roberto Mosca ${ }^{\mathrm{a}^{*}}$ \\ ${ }^{a}$ IMEM-CNR, Parco Area delle Scienze 37/a, 43124 Parma, Italy. \\ b Department of Chemistry “G. Ciamician”, University of Bologna, Via Selmi 2, 40126 \\ Bologna, Italy.
}

${ }^{c}$ Department of Chemistry GIAF, University of Parma, Via Usberti 17/A, 43124, Parma, Italy.

Corresponding Author:

*Roberto Mosca, Senior Scientist

IMEM-CNR

Parco Area delle Scienze 37/A

43124 Parma (Italy)

Telephone +390521 269214

E-mail: mosca@imem.cnr.it

\begin{abstract}
The influence of thermal treatments on the properties of mixed bromide-iodide organolead perovskites $\left(\mathrm{MAPbI}_{3-\mathrm{x}} \mathrm{Br}_{\mathrm{x}}, \mathrm{MA}=\mathrm{CH}_{3} \mathrm{NH}_{3}\right)$ is investigated in films prepared in air by single-step solution processes based on different precursor solutions. Initially, the bandgap energy $\left(E_{G}\right)$ dependence on composition is reconsidered on films obtained by mixtures of tri-halide solutions. An $E_{G}(x)$ relation is obtained that is expected to be independent of the film properties and can be used to assess perovskite composition. In these samples recombination centres are observed whose energy depth increases with $\mathrm{x}$, likely involving the simultaneous presence of iodide and bromide, while the Urbach energy increases with the grain surface-to-volume ratio, which points out that the defects giving sub-bandgap absorption originate from grain boundaries. Tri-halide mixtures allow perovskite synthetic processes suitable for solar cell production, being fast and reproducible. A slight $\mathrm{MABr}$ excess in the solution made of $\mathrm{MABr}$ and $\mathrm{PbI}_{2}$ gives $\mathrm{MAPbI}_{2} \mathrm{Br}$
\end{abstract}


films free of $\mathrm{PbI}_{2}$ phases and with a high compositional stability, but non-radiative recombination channels can make the material not appropriate for high efficiency solar cells. Finally, the solution made of MAI and $\mathrm{PbBr}_{2}$ (3:1 molar ratio) is the less promising for solar cell production because its non-stoichiometric nature synthesis reproducibility an issue.

\section{Introduction}

After $\mathrm{CH}_{3} \mathrm{NH}_{3} \mathrm{PbI}_{3}$-sensitized all-solid-state solar cells were first demonstrated, ${ }^{1}$ hybrid organolead halide perovskites $\left(\mathrm{CH}_{3} \mathrm{NH}_{3} \mathrm{PbX}_{3}, \mathrm{X}=\right.$ halogen $)$ have gone attracting an enormous deal of attention as they hold the promises to allow cost effective, easily processable, efficient and versatile solar cell. Indeed, although initially the most efficient nanostructured perovskite solar cells exploited $\mathrm{CH}_{3} \mathrm{NH}_{3} \mathrm{PbI}_{3}$ light absorbers, mainly due to the high absorption coefficient of this material, ${ }^{2}$ it was soon demonstrated that the $\mathrm{CH}_{3} \mathrm{NH}_{3} \mathrm{PbI}_{3-\mathrm{x}} \mathrm{Cl}_{\mathrm{x}}$ mixed halide perovskite may be suitably used as both light absorber and charge transporter. ${ }^{3}$ This directed the attention towards planar heterojunction structures due to their simpler planar architecture and potential in the reduction of process temperatures.

A further degree of versatility was offered by perovskites incorporating both iodide and bromide halides $\left(\mathrm{CH}_{3} \mathrm{NH}_{3} \mathrm{PbI}_{3-\mathrm{x}} \mathrm{Br}_{\mathrm{x}}\right)$ since the bandgap can be tuned by adjusting the component $\mathrm{I} / \mathrm{Br}$ ratio to cover almost the whole visible spectrum. ${ }^{4}$ Noh et al., who first demonstrated nanostructured solar cells based on $\mathrm{I} / \mathrm{Br}$ mixed-halide perovskites, ${ }^{4}$ achieved for $\mathrm{x}=0.6$ an efficiency of more than $10 \%$ joined to an improved long-term device stability with respect to $\mathrm{CH}_{3} \mathrm{NH}_{3} \mathrm{PbI}_{3}$. The same group recently enhanced the maximum efficiency to above $16 \%$ by modifying the perovskite synthetic procedure, ${ }^{5}$ which confirmed that optimizing the perovskite preparation is a key tool to improve the photovoltaic performances of these devices. Besides, the use of $\mathrm{CH}_{3} \mathrm{NH}_{3} \mathrm{PbI}_{3-\mathrm{x}} \mathrm{Br}_{\mathrm{x}}(\mathrm{x}=0.6)$ perovskite films allowed the fabrication of planar heterojunction solar cells with efficiencies up to $13.1 \%,{ }^{6}$ thus making $\mathrm{I} / \mathrm{Br}$ perovskites very interesting also for planar devices.

In this rapidly evolving scenario, many papers have been published dealing with the device PV performances as determined by the use of different perovskite materials and synthetic procedures, hole transporting materials, photoanodes and solar cell structures, as shown in several reviews. ${ }^{7-12}$

In the case of $\mathrm{MAPbI}_{3}$. and $\mathrm{MAPbI}_{3-\mathrm{x}} \mathrm{Cl}_{\mathrm{x}}$ halide perovskites, the possible relations existing between perovskite properties and processes followed to prepare the material were mainly devoted to features such as morphology and light absorption efficiency, ${ }^{13,14}$ since bandgap energy and crystal structure are nearly independent of the preparation procedures (e.g. substrate used, ${ }^{15}$ annealing time and temperature ${ }^{14}$ ). Besides, in both $\mathrm{MAPbI}_{3}$. and $\mathrm{MAPbI}_{3-\mathrm{x}} \mathrm{Cl}_{\mathrm{x}}$ perovskites an optical bandgap energy of 
about $1.6 \mathrm{eV}\left[{ }^{16,17}\right]$ is measured while the crystal structure is tetragonal at room temperature ${ }^{8}$ with comparable lattice constants, ${ }^{15}$ the incorporation of chloride having negligible impact on the original crystal structure due to the considerably low level of allowed $\mathrm{Cl}$ doping. ${ }^{12,17,18}$ Contrary to $\mathrm{MAPbI}_{3}$ and $\mathrm{MAPbI}_{3-\mathrm{x}} \mathrm{Cl}_{\mathrm{x}}$, organolead $\mathrm{I} / \mathrm{Br}$ mixed-halide perovskites are particularly suitable for investigating the influence of preparation procedures on perovskite properties, since any composition change comes together with changes in crystal structure and absorption onset that are promptly monitored by XRD diffraction patterns and optical absorption spectra, respectively. Thus studying how $\mathrm{MAPbI}_{3-\mathrm{x}} \mathrm{Br}_{\mathrm{x}}$ properties vary with synthetic procedures may give some hints concerning processes leading to the formation of the other perovskites.

Here we report a thorough investigation into the influence of the preparation procedures on the properties of organolead $\mathrm{I} / \mathrm{Br}$ mixed-halide perovskites prepared from single step solution processes. We used the three precursor solutions proposed in the literature: i) mixtures of $\mathrm{MAPbI}_{3}$ and $\mathrm{MAPbBr}_{3}$ solutions, ${ }^{4}$ ii) MABr and $\mathrm{PbI}_{2}\left(1: 1\right.$ molar ratio) in $\mathrm{N}, \mathrm{N}$-dimethylformamide (DMF), ${ }^{19}$ and iii) MAI and $\mathrm{PbBr} 2(3: 1$ molar ratio) dissolved in DMF. ${ }^{20}$ Syntheses were performed in ambient air because there is a persisting interest towards cell preparation procedures to be fully performed in ambient air for ease of fabrication that is most important for industrial use. Besides, even if it is known that moisture may degrade both perovskite ${ }^{21}$ and solar cells, ${ }^{4}$ recently it was demonstrated that a mild humidity positively affects the perovskite film formation, ${ }^{22-24}$ giving solar cells with remarkable power conversion efficiencies, ${ }^{25}$ which renewed the interest for perovskite preparation in air.

\section{Experimental}

Hybrid perovskite films were synthesized by different precursor solutions prepared by using commercially available compounds. In particular, $\mathrm{PbCl}_{2}$ (Aldrich), $\mathrm{PbI}_{2}$ (Aldrich), $\mathrm{HCl}$ (37\%) (Aldrich), $\mathrm{HI}(57 \%)$ (Aldrich), $\mathrm{CH}_{3} \mathrm{NH}_{2}$ (41\% ethanol solution) (Fluka), and MACl (Fluka) were used without further purification. The intermediate MAI and $\mathrm{MABr}$ compounds were prepared by reacting amine solutions with $\mathrm{HI}$ and $\mathrm{HBr}$, respectively. ${ }^{1,26}$ In particular the MAI compound was prepared by mixing methylamine $\left(\mathrm{CH}_{3} \mathrm{NH}_{2}\right)$ solution (33wt\% in absolute ethanol, Aldrich) with hydroiodic acid (57\% in water, Aldrich) in a 1.2:1 molar ratio, while MABr was prepared by mixing methylamine (41\% in water, Fluka) (40\% in water, Aldrich) with hydrobromic acid (48\% in water, Aldrich) in a 1:1 molar ratio. After stirring the mixture continuously in the ice bath for $2 \mathrm{~h}, \mathrm{CH}_{3} \mathrm{NH}_{3} \mathrm{X}$ was crystallized by removing the 
solvent at $65^{\circ} \mathrm{C}$ for $2 \mathrm{~h}$. The resultant precipitates, in the form of white crystals, were washed three times in diethyl ether, dried overnight under vacuum and then stored in a dark, dry environment.

Mixed I/Br perovskites were synthesized using different approaches for the preparation of the precursor solutions. In the first one, similar to Noh et al. ${ }^{4} \mathrm{CH}_{3} \mathrm{NH}_{3} \mathrm{PbI}_{3}$ and $\mathrm{CH}_{3} \mathrm{NH}_{3} \mathrm{PbBr}_{3}$ solutions were prepared by stirring overnight at $60^{\circ} \mathrm{C}$ equimolar mixtures of the as-synthesized $\mathrm{MAI}$ and $\mathrm{PbI}_{2}$ in $\gamma$-butyrolactone (GBL, 99+\%, Acros Organics) or $\mathrm{MABr}$ and $\mathrm{PbBr}_{2}$ in $\mathrm{N}, \mathrm{N}$-dimethylformamide (DMF, 98\%, Fluka) to obtain $0.785 \mathrm{M}$ solutions. At this concentration, both solutions appeared clear when cooled down to room temperature. The solutions used to achieve $\mathrm{CH}_{3} \mathrm{NH}_{3} \mathrm{PbI}_{3-\mathrm{x}} \mathrm{Br}_{\mathrm{x}}$ films were prepared by mixing the $\mathrm{CH}_{3} \mathrm{NH}_{3} \mathrm{PbI}_{3}$ and $\mathrm{CH}_{3} \mathrm{NH}_{3} \mathrm{PbBr}_{3}$ precursor solutions in the (3-x):x volume ratio and then magnetically stirring for 5 min just before spin coating.

The second procedure allowed $\mathrm{CH}_{3} \mathrm{NH}_{3} \mathrm{PbI}_{2} \mathrm{Br}$ perovskite to be achieved by using a precursor solution prepared by dissolving $\mathrm{MABr}$ in DMF to obtain a $0.493 \mathrm{M}$ solution and then adding $\mathrm{PbI}_{2}$ with a molar ratio of 1.2:1 between $\mathrm{MABr}$ and $\mathrm{PbI}_{2}$, instead of 1:1. ${ }^{19}$ Finally, the solution was stirred at room temperature for 1 hour until a bright yellow solution was achieved.

The third solution was analogous to that proposed for the methylammonium lead iodide chloride perovskite: ${ }^{27} \mathrm{CH}_{3} \mathrm{NH}_{3} \mathrm{I}$ was dissolved in DMF to obtain a $0.943 \mathrm{M}$ solution and then $\mathrm{PbBr}_{2}$ was added to obtain a 3:1 molar ratio between $\mathrm{CH}_{3} \mathrm{NH}_{3} \mathrm{I}$ and $\mathrm{PbBr}_{2}$. After 2 hours stirring a bright yellow solution was achieved.

For the sake of brevity, we will refer to the above precursor solutions as " $\mathrm{I}_{3} / \mathrm{Br}_{3}$ mixture", "1.2:1" and "3:1", respectively.

In all the cases, 1"x 1" glass microscope slides were cleaned by organic solvents and treated in an oxygen plasma. The precursor solution was spin coated at $2500 \mathrm{rpm}$ for $60 \mathrm{~s}$ and then dried on a hot plate to allow the perovskite film formation. Solution processing and spin coating were carried out in ambient air with humidity ranging from $35 \%$ to $55 \%$. In selected cases, both steps were performed in an Ar-filled glove box.

XRD characterization was performed by using a Thermo X'tra powder diffractometer equipped with $\mathrm{Cu}$ $\mathrm{K} \alpha$ radiation and a Thermo Electron $\mathrm{Si}(\mathrm{Li})$ solid state detector. Diffraction patterns were collected by $0.05^{\circ} 2 \theta$ steps and counting times ranging from 2 to $10 \mathrm{~s}$ per step. In order to measure non-oriented XRD patterns of the perovskite powders, films were carefully scratched from their substrate by an edged glass slide and supported on zero-background sample holder cut from a quartz crystal.

Diffuse reflectance spectra were collected at room temperature by a double beam spectrophotometer Perkin-Elmer Lambda 45 equipped with the RSA-PE-20 integrating sphere accessory (LabSphere). The 
reflectance data were converted to absorbance mode using the Kubelka-Munk remission function $\mathrm{F}(\mathrm{R})$, which is approximately proportional to the absorption coefficient, according to the relation $\mathrm{F}(\mathrm{R})=(1-\mathrm{R})^{2} / 2 \mathrm{R}$ where $\mathrm{R}$ is the diffuse reflectivity. ${ }^{28,29}$

Steady-state photoluminescence (PL) emission spectra were obtained by exciting the samples with a 325 $\mathrm{nm} \mathrm{HeCd}$ laser radiation.

Morphological characterization was performed by scanning electron microscopy (SEM) by using a Zeiss Auriga Field Emission Microscope (FESEM) operated at $5 \mathrm{kV}$. Films were gold-metallized to reduce charging effects during SEM measurements.

\section{Results and discussion}

Noh et al. ${ }^{4}$ demonstrated that when mixtures of $\mathrm{MAPbI}_{3}$ and $\mathrm{MAPbBr}_{3}$ solutions are used, the perovskite composition reproduces the I:Br molar ratio of the precursor solution, and gave the parabolic dependence on $\mathrm{x}$ of the bandgap energy as determined from the onset of the absorption band. This dependence was used later to assess the composition of $\mathrm{MAPbI}_{3-\mathrm{x}} \mathrm{Br}_{\mathrm{x}}$ perovskites prepared in a two-step procedure. ${ }^{30}$ However, it is well known that measuring the bandgap energy $\left(E_{G}\right)$ from the onset of the absorption band gives results that may depend on film properties different from composition such as film thickness, ${ }^{31}$ while absorption by defect and impurity states causes a blurring of the absorption edge that makes the estimation of $E_{G}$ less precise. ${ }^{32}$ For these reasons, an accurate measurement of the bandgap energy is usually achieved by diffuse reflectance spectroscopy through the Tauc model, ${ }^{31,33}$ i.e. plotting the modified Kubelka-Munk function $(\mathrm{F}(\mathrm{R}) \cdot \mathrm{E})^{2}$ vs photon energy $\mathrm{E}$ and, according to the direct transition equation, extrapolating the linear portion of the curve to $(F(R) \cdot E)^{2}=0$.

In order to achieve an $E_{G}(x)$ expression independent of the film properties, we first reconsidered the dependence on $\mathrm{x}$ of $\mathrm{E}_{\mathrm{G}}$ based on the Tauc analysis by synthesizing and studying $\mathrm{MAPbI}_{3-\mathrm{x}} \mathrm{Br}_{\mathrm{x}}$ perovskites prepared by $\mathrm{I}_{3} / \mathrm{Br}_{3}$ mixture solutions. SEM-EDS measurements performed on a set of calibration samples pointed out that the composition of the obtained perovskites closely reproduces that of the corresponding precursor solution. The results of the structural characterization confirm that a complete solid solution forms for the whole composition range $0 \leq x \leq 3$ (Figure1a). Figure $1 \mathrm{~b}$ shows the variation of the lattice parameters with the composition. The tetragonal symmetry of the crystal structure is initially retained by increasing $\mathrm{x}$, but, in agreement with Noh et $\mathrm{al}^{4}{ }^{4}$, starting from $\mathrm{x}=0.57$ the structure becomes cubic; in this region the lattice volume decreases monotonically with $\mathrm{x}$, but a small negative deviation from the Vegard law is observed indicating a stabilizing character of the interactions in the mixed halogen compound. 

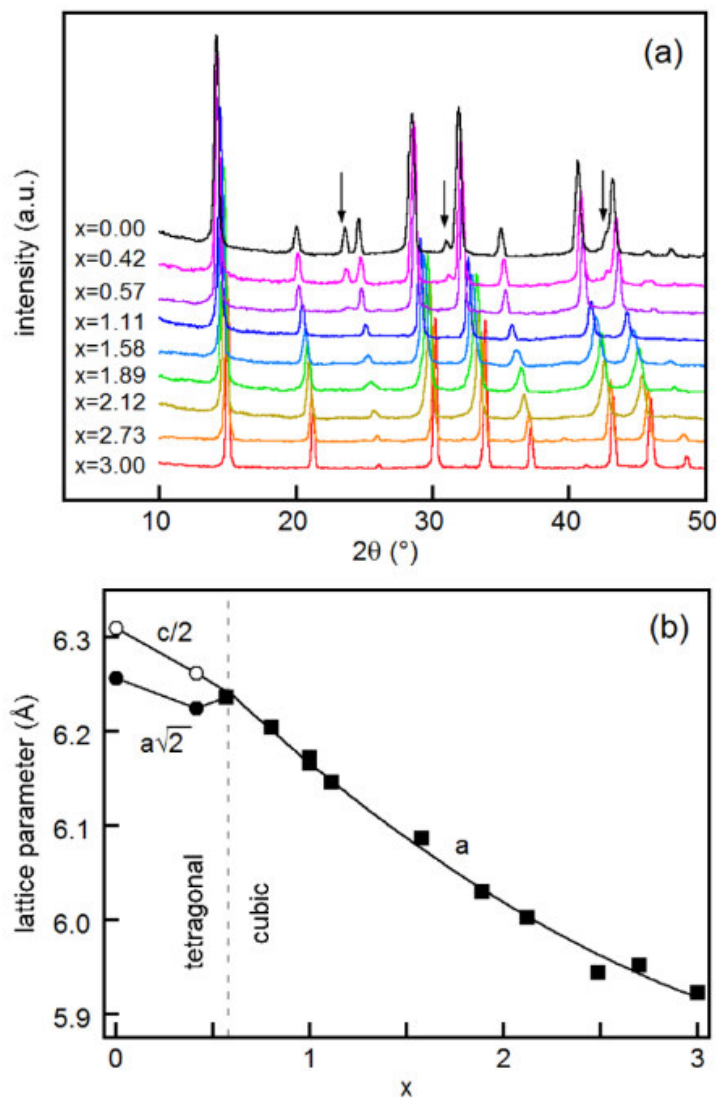

Fig. 1. Composition dependent evolution of (a) powder XRD pattern and (b) lattice parameters for the $\mathrm{MAPbI}_{3-\mathrm{x}} \mathrm{Br}_{\mathrm{x}}$ perovskites; down arrows indicate the characteristic diffraction peaks of the tetragonal phase.

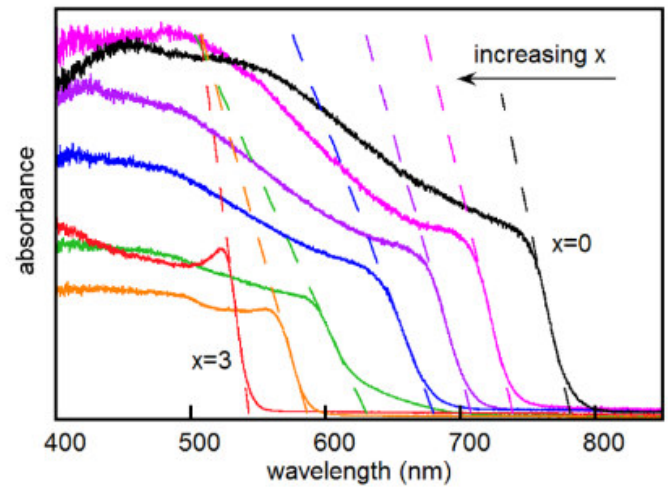

Figure 2 Absorbance spectra of $\mathrm{MAPbI}_{3-\mathrm{x}} \mathrm{Br}_{\mathrm{x}}$ films with different $\mathrm{x}$ values. Dashed lines were used to assess the bandgap energy from the absorption onset.

Diffuse reflectance measurements show that the absorbance onset blue shifts as the $\mathrm{Br}$ concentration increases (Figure 2) and that spectra are featureless above the excitonic structure and band gap, consistently with previous literature data. ${ }^{4,34}$ The $E_{G}$ values we obtained by the Tauc analysis (Figure 3) are larger than those achieved from the position of the absorption onset, ${ }^{4}$ likely due to the different methods used to determine the optical bandgap. Indeed, from the absorbance onset of the spectra in Figure 2 we

obtained values that are few meV tens smaller than those derived by the Tauc analysis and not far from the curve given in Ref.4 (Figure 3)

The behavior of $E_{G}(x)$ shown in Figure 3 deviates slightly from the linear dependence, displaying a downward bowing that can be fitted to a quadratic expression in $\mathrm{x}$ :

$$
E_{G}(x)=1.604+0.176 x+0.019 x^{2}
$$

This $E_{G}(x)$ relation is expected to be independent of the film properties and can be written as:

$$
E_{G}(x)=E_{I 3}+\left(E_{B r 3}-E_{I 3}-b\right) \frac{x}{3}+b\left(\frac{x}{3}\right)^{2}
$$


where $\mathrm{E}_{\mathrm{I} 3}$ and $\mathrm{E}_{\mathrm{Br} 3}$ are the bandgap of $\mathrm{MAPbI}_{3}$ and $\mathrm{MAPbBr}_{3}$, respectively, and $b$ the so called bowing parameter that accounts for the effects of composition disorder on the conduction and valence band edges. ${ }^{35}$ Fitting Eq. (2) to the experimental data of Figure 3 gives $\mathrm{E}_{\mathrm{I} 3}=1.604 \mathrm{eV}, \mathrm{E}_{\mathrm{Br} 3}=2.307 \mathrm{eV}$ and $\mathrm{b}=0.175 \mathrm{eV}$. $\mathrm{E}_{\mathrm{I} 3}$ and $\mathrm{E}_{\mathrm{Br} 3}$ agree with values reported in the literature for $\mathrm{MAPbI}_{3}$ prepared in an inert atmosphere ${ }^{16,17}$ and $\mathrm{MAPbBr}_{3},{ }^{36}$ while the bowing parameter $\mathrm{b}$ is about one-half the $0.33 \mathrm{eV}$ value given in Ref.4, which points out that compositional disorder is low even if samples were prepared in ambient air. We achieved further information about the dependence on $\mathrm{x}$ of disorder by analyzing the exponential decay of the sub-bandgap absorbance, that is commonly described by the empirical Urbach rule ${ }^{37}$ $\mathrm{A} \propto \exp \left(\mathrm{E} / \mathrm{E}_{0}\right)$, where $\mathrm{A}$ is the absorbance, $\mathrm{E}$ the photon energy, and $E_{0}$ the characteristic energy named the Urbach energy that represents the width of the exponential Urbach tail. Although no theoretical derivation of the Urbach rule appears to be universally accepted, there is a general consensus that the Urbach tail in crystalline semiconductors is related to the dynamic phonon disorder and static structural disorder ${ }^{38}$ that may arise from lattice point defects, dislocations, strain, deviation from ideal stoichiometry as well as the effect of the grain surface. ${ }^{39}$ The Urbach energy calculated from the linear portion of the $\ln F(R)$ vs. E graph is shown in Figure 4 as a function of $x$. $E_{0}$ is $27 \mathrm{meV}$ for the pure triiodide perovskite and increases slightly with the bromide content up to $\mathrm{x}=0.57$, where the crystal structure transforms from tetragonal to cubic. For larger $\mathrm{x}$, the Urbach energy increases more rapidly until it reaches a maximum of $\sim 85 \mathrm{meV}$ at $\mathrm{x}=1.89$ and then decreases down to $34 \mathrm{meV}$ for the pure tri-bromide perovskite. An analogous behavior was recently shown for samples prepared by a single step solution process similar to the one used here,${ }^{34}$ but the maximum $\mathrm{E}_{0}$ value of $90 \mathrm{meV}$ was 
found at $\mathrm{x}=2.4$. Besides for $\mathrm{MAPbI}_{3}$ an $\mathrm{E}_{0}=15 \mathrm{meV}$ value was obtained, that is the same value reported previously ${ }^{40}$ on films prepared by a two-steps synthesis procedure. Both these results were obtained by photothermal deflection spectroscopy (PDS) on samples prepared in an inert atmosphere, while in the present work perovskites were synthesized in ambient air. However, we found that samples prepared in an Ar-filled glove box show $\mathrm{E}_{0} \approx 29.0 \mathrm{meV}$, which is comparable with the $27 \mathrm{meV}$ of samples prepared in air, thus ruling out that sample preparation in air is responsible for the higher $\mathrm{E}_{0}$ values we found.

As for the nature of the disorder responsible for the Urbach energies measured in our samples, it is worth noting that the $\mathrm{E}_{0}$ behavior shown in Figure 4 cannot be justified by any known property of $\mathrm{MAPbI}_{3-\mathrm{x}} \mathrm{Br}_{\mathrm{x}}$ perovskites. The photoluminescence (PL) peak previously reported for $\mathrm{MAPbI}_{3-\mathrm{x}} \mathrm{Br}_{\mathrm{x}}$ showed a full width half maximum (FWHM) dependence on $\mathrm{x}$ similar to that of the Urbach energy. ${ }^{34}$ This was considered as an indication that emission and absorption originate from similar states, but the origin of such states was not discussed. In the present case the main feature of the PL spectra is a broad peak (Figure 5A) whose FWHM shows a maximum (Figure 5B) near the composition range where the Urbach energy is maximum (Figure 4). The peak is located at $1.60 \mathrm{eV}(774 \mathrm{~nm})$ and 2.28 $\mathrm{eV}(543 \mathrm{~nm})$ for $\mathrm{MAPbI}_{3}$ and $\mathrm{MAPbBr}_{3}$, respectively, in agreement with previous literature, ${ }^{16,41}$ while for intermediate compositions $(0<x<3)$ the peak maximum falls in the $1.67-1.78$ $\mathrm{eV}$ range without a definite dependence on $\mathrm{x}$. This behavior is not consistent with the gradual shift reported in ref ${ }^{34}$ where, however, PL was excited by a pulsed laser system with a 400nm photon
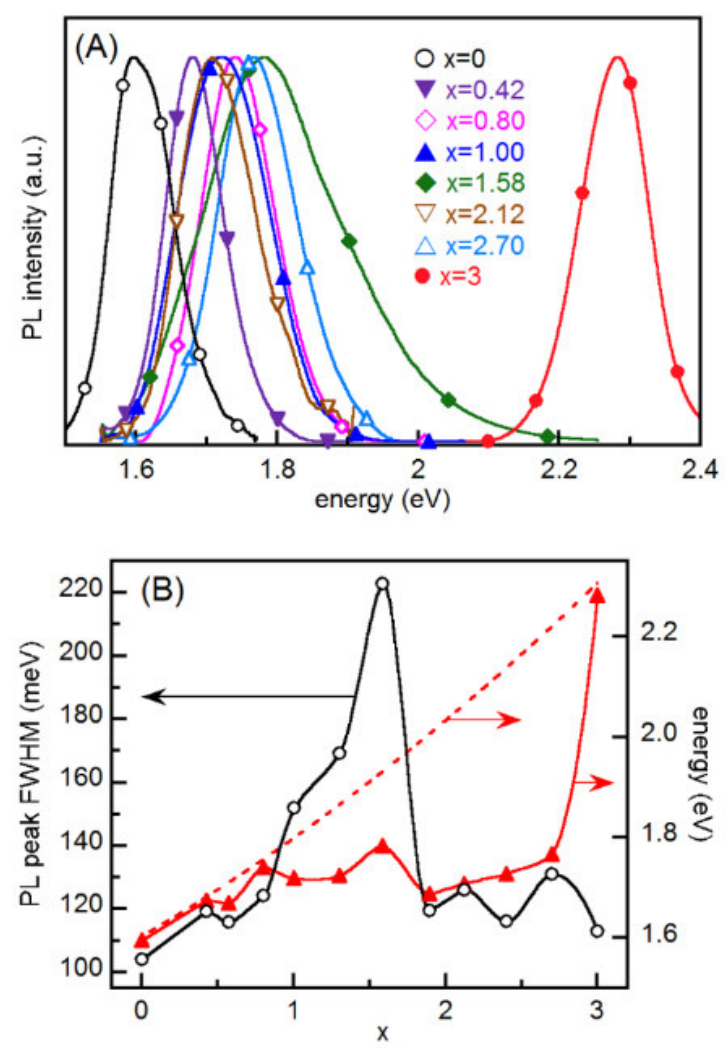

Figure 5 (A) PL spectra of $\mathrm{MAPbI}_{3-\mathrm{x}} \mathrm{Br}_{\mathrm{x}}$ films and (B) Dependence on $x$ of the PL peak FWHM and energy of the peak maximum. Dashed line is $\mathrm{E}_{\mathrm{G}}(\mathrm{x})$ obtained from Eq.1. In (B) Interpolating full lines are used as guide for the eye. wavelength. By comparing the energy of the PL peak maximum with the $\mathrm{E}_{\mathrm{G}}(\mathrm{x})$ for the different bromide contents (Figure 5B), we observe that emission peaks near the band edges for small $\mathrm{x}$ values, but does not follow the bandgap energy change when $\mathrm{x}$ increases. This indicates that PL emission involves recombination centers that deepen in the bandgap as 
$\mathrm{x}$ increases. Besides, reaching $\mathrm{x}=3$ makes the peak energy suddenly rise, so that PL peaks near the band edges, as found for small $\mathrm{x}$ values. This hints that the recombination centers come from the simultaneous presence of iodide and bromide in the perovskite lattice. Work is in progress to get deeper insights about the origin of these defects and verify their possible relation with the dependence on $\mathrm{x}$ of the Urbach tail.

We also analyzed the FWHM of the XRD patterns obtained from powdered samples in the cubic phase and found that its behavior resembles closely the $\mathrm{E}_{0}$ one, reaching its maximum in the same composition range where $\mathrm{E}_{0}$ is maximum (Figure 4). According to the Scherrer law this FWHM behavior may be considered to originate from a variation with $\mathrm{x}$ of the grain size, that is then expected to be minimum for $\mathrm{x}=1.89$. SEM images shown in Figure 6 confirm this dependence on $\mathrm{x}$ of the grain size. Indeed films obtained by different compositions of the " $\mathrm{I}_{3} / \mathrm{Br}_{3}$ mixture" solution are made of perovskite islands having different shapes and sizes, albeit in all the cases the surface coverage is low (Figures 6a, 6c, 6e, 6g, 6i, and 6m). This is typical of hybrid perovskites deposited in usual single step processes from stoichiometric GBL or DMF solutions, ${ }^{42}$ as uniform films were obtained from single step processes only through approaches specifically developed for this purpose..$^{5,13,43,44}$ Higher-magnification SEM images show that islands result from the aggregation of grains whose morphology and size depend on x. In particular, a gradual decrease of the average grain size is observed for x up to 1.89 (Figures 6b, 6d, 6f, and 6h). In some cases, such as for $x=1.0$ (Figure 6d),
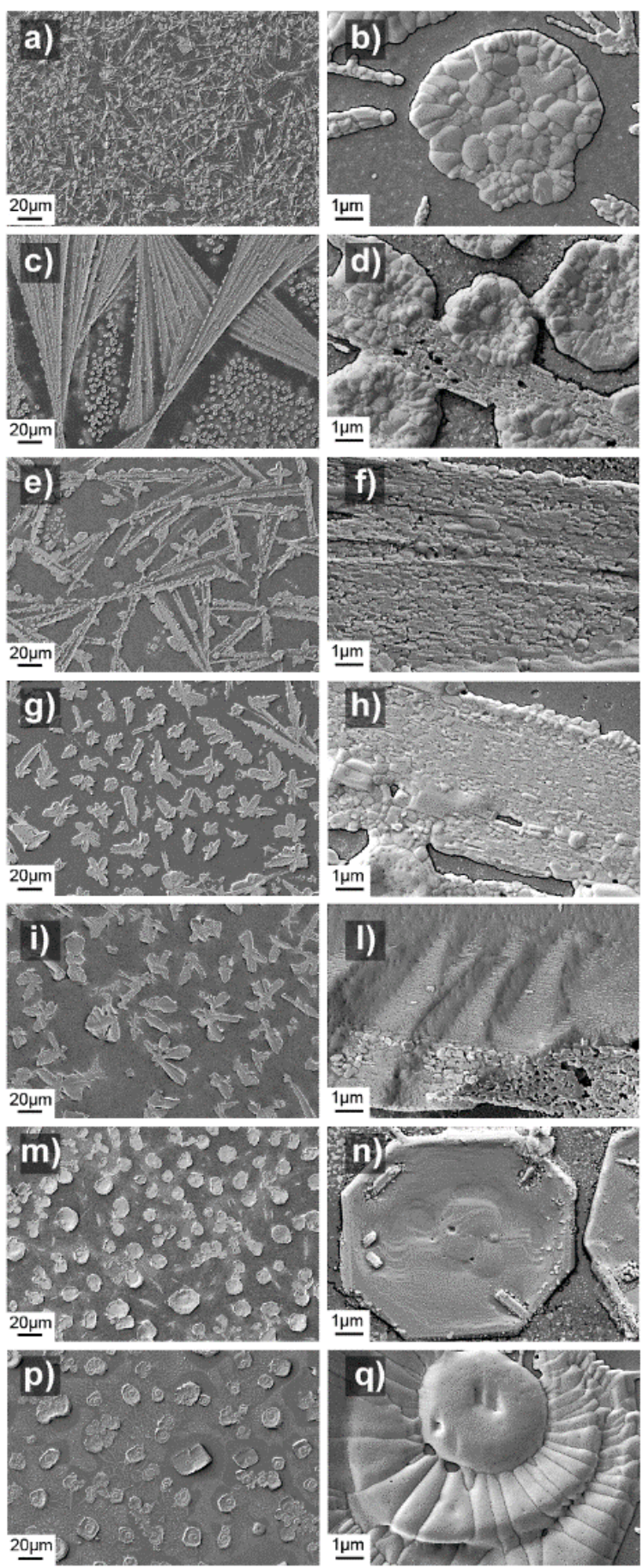

Fig. 6 SEM images of $\mathrm{MAPbI}_{3-\mathrm{x}} \mathrm{Br}_{\mathrm{x}}$ films with $(\mathrm{a}, \mathrm{b})$ $\mathrm{x}=0.57$, (c, d) $\mathrm{x}=1.0$, (e, f) $\mathrm{x}=1.58,(\mathrm{~g}, \mathrm{~h}) \mathrm{x}=1.89$, (i, l) $\mathrm{x}=2.12$, $(\mathrm{m}, \mathrm{n}) \mathrm{x}=2.70$, and $(\mathrm{p}, \mathrm{q}) \mathrm{x}=3.0$. 
different size domains coexist in a sort of transition from relatively large to small grains. For $\mathrm{x}>1.89$ grains appear less defined in the SEM images (Figure 61 and 6n), but an increase of the grain size can be envisaged in the regions where grains can be observed. The trend is finally confirmed for $\mathrm{x}=3$ (Figure $6 q)$ since the average grain size is definitely the largest of the whole set. These results, with those shown in Figure 4, point out that the Urbach energy increases when the grain size decreases, i.e. when the grain surface-to-volume ratio increases, thus suggesting the dominant role of the grain boundary regions. This strongly supports the hypothesis that sub-bandgap absorption is related to defect states located at the grain boundaries, which is consistent with the observation that solar cell efficiency increases with grain size. $^{45}$

When considering the influence of the preparation procedure on the properties of perovskite obtained by the $\mathrm{I}_{3} / \mathrm{Br}_{3}$ mixture, some attention must be devoted to the suitability of the thermal treatment at $100^{\circ} \mathrm{C}$ for $5 \mathrm{~min}$ we used. The annealing temperature of $100^{\circ} \mathrm{C}$ is used frequently when lead halide perovskites are synthesized from single step solution methods. ${ }^{1,3,19,27,36,46}$ On the contrary, most of the treatments reported in the literature last from $15^{1,46}$ to $45 \mathrm{~min}, 3,36$ while a 5 min annealing was used only in few cases, e.g. in $\mathrm{MAPbI}_{3-\mathrm{x}} \mathrm{Br}_{\mathrm{x}}{ }^{4}{ }^{4} \mathrm{MAPbI}_{2} \mathrm{Br},{ }^{47}$ and $\mathrm{MAPbI}_{3} .{ }^{48}$ We analyzed $\mathrm{MAPbI}_{3}(\mathrm{x}=0)$ and $\mathrm{MAPbI}_{2} \mathrm{Br}(\mathrm{x}=1)$ films treated at $100^{\circ} \mathrm{C}$ for different durations $\Delta \mathrm{t}_{\mathrm{A}}$. In $\mathrm{MAPbI}_{3}$, both absorption spectra and XRD patterns are nearly independent of $\Delta \mathrm{t}_{\mathrm{A}}$ up to $60 \mathrm{~min}$ (Figure 7a). In the case of $\mathrm{MAPbI}_{2} \mathrm{Br}$ (Figure 7b), films treated for 5 and 10 min show comparable XRD patterns and absorption spectra, while those annealed for $20 \mathrm{~min}$ point out a slight blue shift of the absorption onset together with the appearance of a XRD peak at $2 \theta=12.7^{\circ}$. This peak, that was found also in $45 \mathrm{~min}$ annealed films, ${ }^{34}$ is ascribed to the (001) Bragg reflection of a hexagonal $\mathrm{PbI}_{2}$ impurity phase $^{42}$ and is generally considered as a telltale of perovskite degradation. In the case of $\mathrm{MAPbI}_{3}, \mathrm{PbI}_{2}$ islands form at the surface of the perovskite grain when annealing is prolonged. ${ }^{49}$ Here, the blue shift

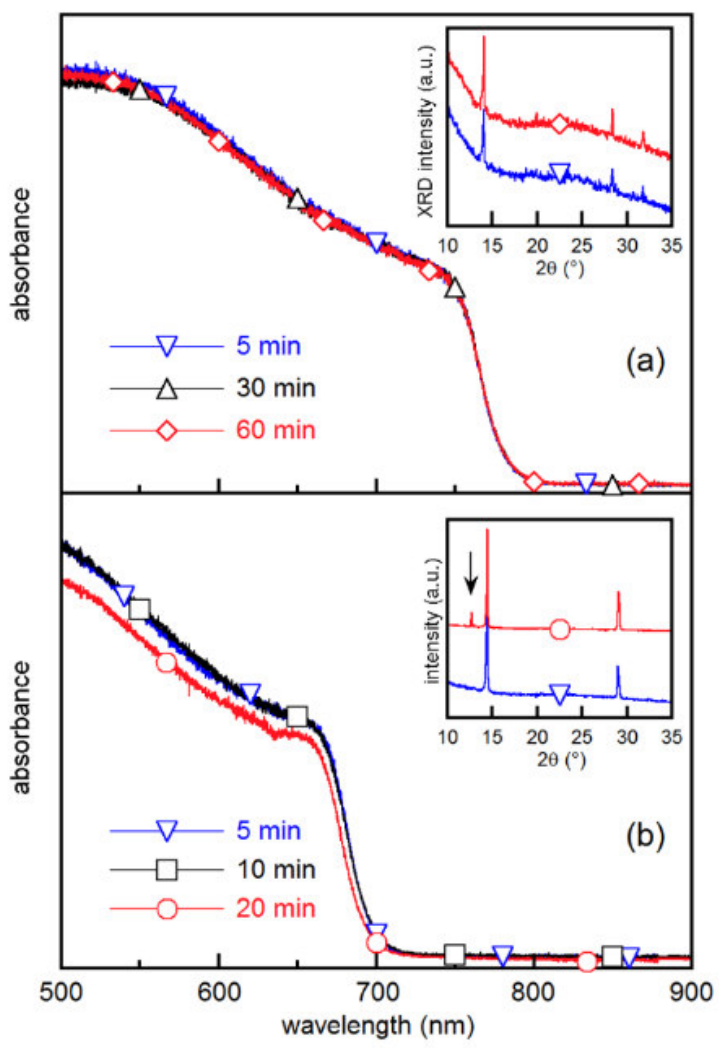

Figure 7 Absorbance spectra of (a) $\mathrm{MAPbI}_{3}$ and (b) $\mathrm{MAPbI}_{2} \mathrm{Br}$ films annealed at $100^{\circ} \mathrm{C}$ for different times, as indicated. The insets show the XRD patterns of films annealed for (a) 5 or $60 \mathrm{~min}$ and (b) 5 or $20 \mathrm{~min}$.Down arrow points out the $\mathrm{PbI}_{2}$ peak. 
of the bandgap suggests that degradation involves also kinetic reactions that affect the perovskite composition in the whole grain volume.

Owing to these results, we conclude that perovskites obtained by $\mathrm{I}_{3} / \mathrm{Br}_{3}$ mixtures form properly at $100^{\circ} \mathrm{C}$ for relatively short $(5 \mathrm{~min})$ thermal treatments and are stable up to $10 \mathrm{~min}$ annealing, which makes the synthetic process suitable for solar cell production, being fast and reproducible enough. Besides, since the absorption profiles are stable for treatments long up to $10 \mathrm{~min}$, we consider as complete the conversion to the final perovskite after $5 \mathrm{~min}$ treatment. This means that the functional dependence of $\mathrm{E}_{\mathrm{G}}(\mathrm{x})$ given by $\mathrm{Eq} .1$ can be used to assess the bromide content in the $\mathrm{MAPbI}_{3-\mathrm{x}} \mathrm{Br}_{\mathrm{x}}$ perovskites, as we have done hereafter.

After the $\mathrm{I} 3 / \mathrm{Br} 3$ mixture, we studied the precursor solution made of $\mathrm{MABr}$ and $\mathrm{PbI}_{2}$ in $\mathrm{DMF}$ proposed by Qiu et al., ${ }^{19}$ who obtained the $\mathrm{MAPbI}_{2} \mathrm{Br}$ perovskite by spin coating a 1:1 stoichiometric solution followed by an annealing in $\mathrm{N}_{2}$ atmosphere at $100{ }^{\circ} \mathrm{C}$. We found by XRD patterns that perovskite crystallizes systematically in the cubic $(\mathrm{Pm} \overline{3} \mathrm{~m})$ structure, but in our samples prepared in air we often detected also the $\mathrm{PbI}_{2}$ peak at $2 \theta=12.7^{\circ}$ (Figure 8A pattern a), which indicates perovskite degradation. On the other hand, no evidence of $\mathrm{PbI}_{2}$ formation was found when either precursor preparation and film synthesis were carried out in an Ar filled glove box or films were prepared in air from a MABr-rich precursor solution (in our case MABr:PbI ${ }_{2}$ molar ratio was $\left.1.2: 1\right)$. These results suggest that the $\mathrm{PbI}_{2}$ presence is due to the interaction of $\mathrm{MABr}$ salt with the ambient moisture
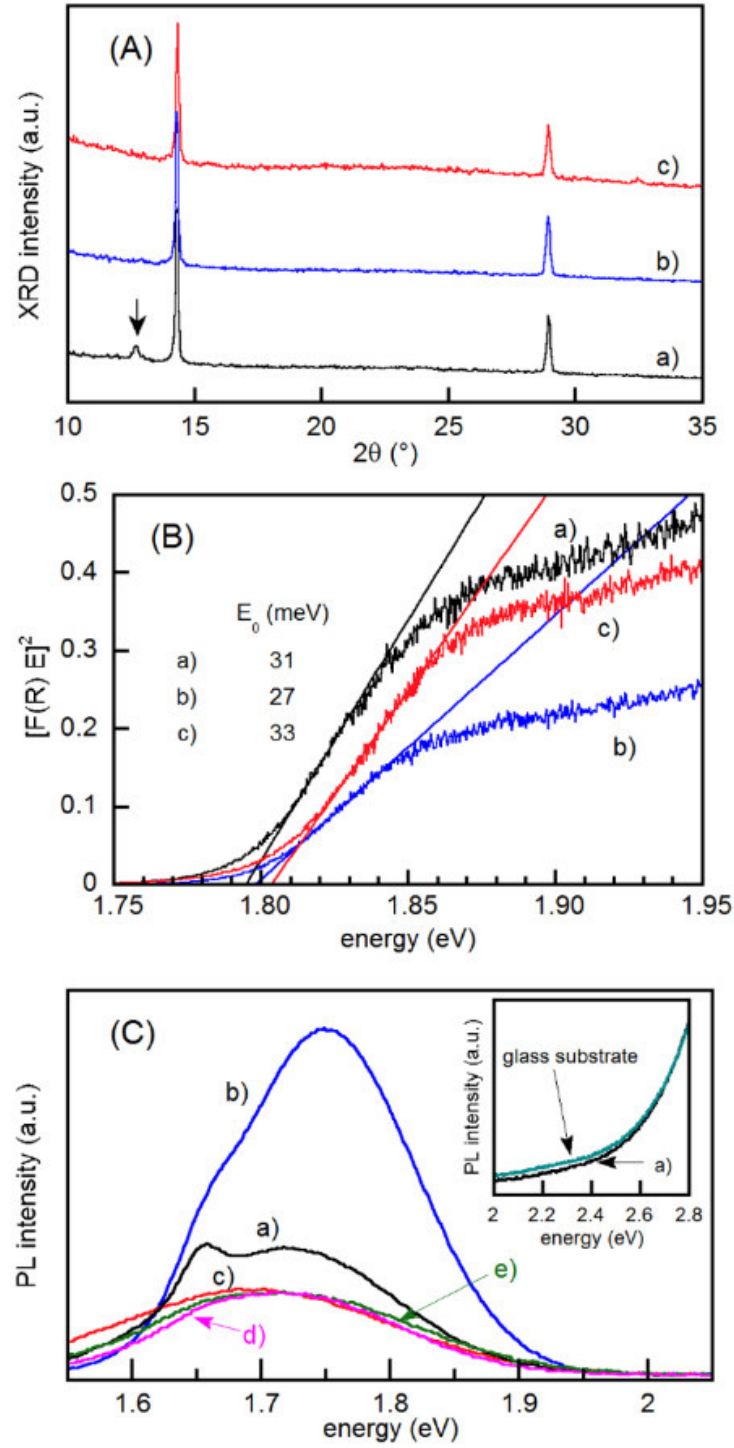

Fig. 8 (A) XRD patterns (B) Tauc plots, and (C) PL spectra of $\mathrm{MAPbI}_{2} \mathrm{Br}$ films prepared by a $\mathrm{MABr}: \mathrm{PbI}_{2}$ solution with a molar ratio of either $1: 1$ in a) air and $b$ ) Ar-filled glove box, or 1.2:1 in c) air. Down arrow in (A) indicates the position of the $\mathrm{PbI}_{2}$ peak. In (C) spectra d) and e) refer to samples annealed at $100^{\circ} \mathrm{C}$ for $10 \mathrm{~min}$ and $110^{\circ} \mathrm{C}$ for $20 \mathrm{~min}$, respectively. The inset shows the spectrum of the glass substrate and the a) one in the energy range where the $\mathrm{PbI}_{2}$ peak is expected. 
that makes a $\mathrm{MABr}$ aliquot unavailable for perovskite formation, thus leaving a corresponding amount of $\mathrm{PbI}_{2}$ unreacted.

Figure $8 \mathrm{~B}$ shows that the MABr excess leads to a minor blue shift of the absorption profile with respect to samples prepared by 1:1 solutions in either air or inert atmosphere. Indeed, the achieved $E_{G}$ values are about $1.80 \mathrm{eV}$ in all the cases, which indicates that the achieved compositions are actually $\mathrm{x} \approx 1$ according to Eq.1, in agreement with the $1.8 \mathrm{eV}$ bandgap energy reported for $\mathrm{MAPbI}_{2} \mathrm{Br}$ nanosheet layers. ${ }^{48} \mathrm{In}$ these samples the Urbach energy vary slightly with the synthetic procedures used, even preparation in argon results in a slightly smaller $\mathrm{E}_{0}$ value. On the contrary, PL spectra (Figure $8 \mathrm{C}$ ) point out that both $\mathrm{MABr}$ excess and atmosphere affect the perovskite emission properties. In particular, all the spectra show a structured band in the same energy range as the $\mathrm{x}=1$ sample in Figure $5 \mathrm{~A}$, which proves that defects responsible for this band are not due to the preparation in air. Samples prepared in inert atmosphere show an enhanced PL with respect to their counterparts prepared in air, which is consistent with the $\mathrm{E}_{0}$ behavior and suggests that non-radiative recombination channels form in $\mathrm{MAPbI}_{2} \mathrm{Br}$ prepared in air. Thus, $\mathrm{MAPbI}_{2} \mathrm{Br}$ preparation in ambient air has no beneficial effect on the perovskite photoluminescence, in contrast with what previously reported for $\mathrm{MAPbBr}_{3}{ }^{23}$ and $\mathrm{MAPbI}_{3-\mathrm{x}} \mathrm{Cl}_{\mathrm{x}}{ }^{22,24}$ films. As for samples prepared in air, the 1.2:1 solution results in a lowering and broadening of the PL band compared to the 1:1 solution (Figure 4c). Finally, it is worth noting that spectra of samples prepared in air from 1:1 solution (inset of Figure 8C) do not show the PL peak at $\sim 2.38 \mathrm{eV}^{42}$ typical of the $\mathrm{PbI}_{2}$ phase observed in the corresponding XRD pattern (Figure 8A), which suggests that this is an impurity phase.

In order to optimize the synthetic process in air by the 1.2:1 solution, we studied the properties of $\mathrm{MAPbI}_{2} \mathrm{Br}$ perovskites obtained for different baking temperatures and durations. Figure 9 shows that all the XRD patterns point out highly oriented pure phase perovskite structures that depend to a minor extent on both temperature $\left(\mathrm{T}_{\mathrm{A}}\right)$ and duration $\left(\Delta \mathrm{t}_{\mathrm{A}}\right)$, thus indicating that the crystal structure of the material is remarkably stable. The absorbance spectra confirm the minor influence of temperature below $120^{\circ} \mathrm{C}$ (Figure $10 \mathrm{~A}$ ) while at $100^{\circ} \mathrm{C}$ increasing the annealing duration from 5 to $60 \mathrm{~min}$ makes absorbance progressively decrease (Figure 10B). In all the cases the bandgap energies we

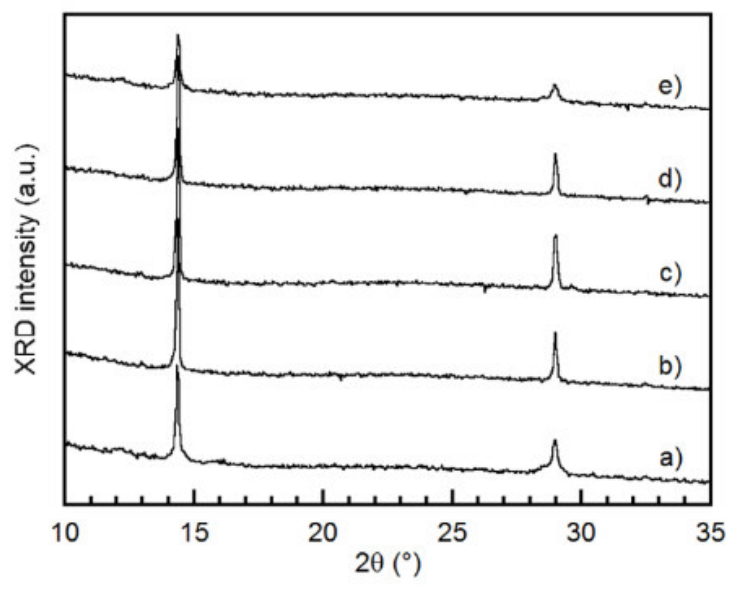

Fig. 9 XRD patterns of $\mathrm{MAPbI}_{2} \mathrm{Br}$ films obtained from the $1.2: 1$ solution by annealing at $100^{\circ} \mathrm{C}$ for a) $5 \mathrm{~min}$, b) $20 \mathrm{~min}$, and c) $60 \mathrm{~min}$, and for $20 \mathrm{~min}$ at d) $120^{\circ} \mathrm{C}$ and e) $80^{\circ} \mathrm{C}$. 
measured were around the $1.80 \mathrm{eV}$ value expected for $\mathrm{MAPbI}_{2} \mathrm{Br}$, thus confirming that material composition is well preserved (insets in Figure 10).

The absorbance spectra confirm the minor influence of temperature below $120^{\circ} \mathrm{C}$ (Figure 10A) while at $100^{\circ} \mathrm{C}$ increasing the annealing duration from 5 to 60 min makes absorbance progressively decrease (Figure 10B). In all the cases the bandgap energies we measured were around the $1.80 \mathrm{eV}$ value expected for $\mathrm{MAPbI}_{2} \mathrm{Br}$, thus confirming that material composition is well preserved (insets in Figure 10A and B). Similarly, the Urbach tail (Figure 10A and B) and PL spectrum (Figure 8C) are weakly affected by the annealing conditions. Thus we can conclude that the $\mathrm{MAPbI}_{2} \mathrm{Br}$ perovskite made using the 1.2:1 solution is compositionally more stable than that obtained for $\mathrm{x}=1$ by the $\mathrm{I}_{3} / \mathrm{Br}_{3}$ mixture, likely due to the presence of the MABr excess that compensates

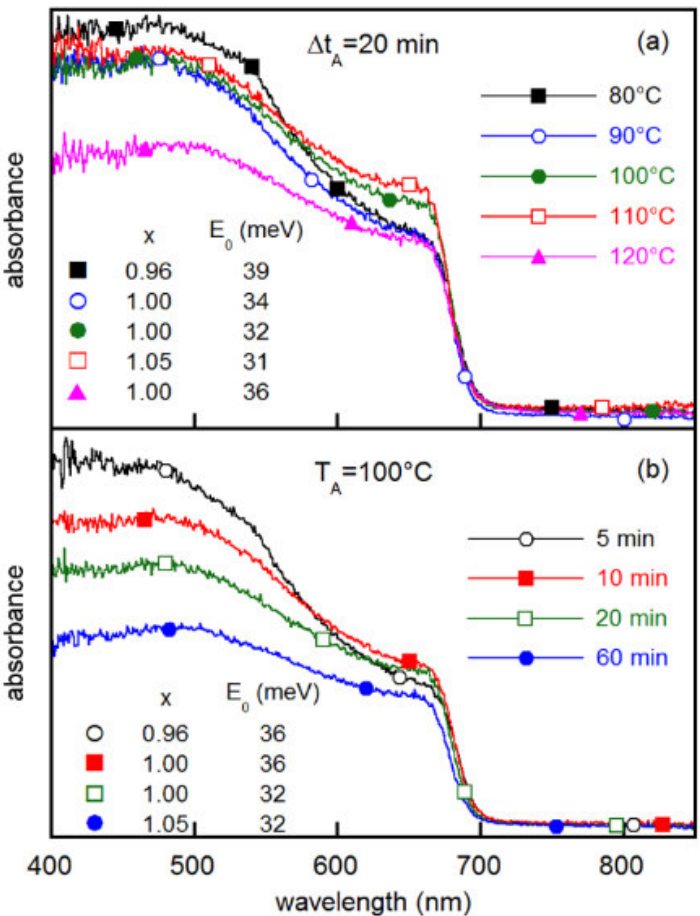

Fig. 10 Absorbance spectra of $\mathrm{MAPbI}_{2} \mathrm{Br}$ films obtained from the 1.2:1 solution by annealing for different (a) temperatures and (b) times, as indicated. Inset tables show the $\mathrm{x}$ and $\mathrm{E}_{0}$ values obtained from each spectrum. Compositions were estimated by Eq.1 from the relevant $\mathrm{E}_{\mathrm{G}}$ values. the losses of the organic material during the annealing process. However, the non-radiative recombination channels systematically pointed out by PL spectra could make MAPbI2Br prepared in air from the 1.2:1 solution not appropriate for high efficiency solar cell.

The last solution we considered is made of MAI and $\mathrm{PbBr}_{2}(3: 1$ molar ratio) dissolved in DMF. This " $3: 1$ " solution is analogous to that used to obtain the $\mathrm{MAPbI}_{3-\mathrm{x}} \mathrm{Cl}_{\mathrm{x}}$ perovskite that initially was believed to have $\mathrm{x}=1,{ }^{27}$ whilst nowadays it is generally accepted that the formation of this compound is prevented by the large difference in the ionic radii of $\mathrm{Cl}^{-}$and $\mathrm{I}^{-}$anions. ${ }^{17}$ In the case of mixed $\mathrm{Br} / \mathrm{I}$ perovskite, an extended solid solution can form, but we found that the final perovskite composition depends strongly on annealing temperature and time. Besides, XRD patterns of films annealed for $60 \mathrm{~min}$ at different temperatures show that there is only a narrow $\mathrm{T}_{\mathrm{A}}$ range around $120^{\circ} \mathrm{C}$ giving highly oriented pure phase perovskite films (Figure 11a). Indeed, films treated at $110^{\circ} \mathrm{C}$ show broadened perovskite peaks at $14.3^{\circ}$ and $28.7^{\circ}$ corresponding to the (100) and (200) perovskite Bragg reflections, respectively. The additional broad peaks appearing at $2 \theta=12.3^{\circ}$ and $16.0^{\circ}$ were found in films prepared by the same $3: 1$ precursor 
solution $^{20}$ and, in close analogy with $\mathrm{MAPbI}_{3-\mathrm{x}} \mathrm{Cl}_{\mathrm{x}}$ films, are considered to originate from intermediate products resulting from the drying process in humid air $^{14}$ and the incorporation of methylammonium halides and their variations. ${ }^{50}$ Similar peaks were not observed for either $\mathrm{I}_{3} / \mathrm{Br}_{3}$ mixture or 1.2:1 precursor solutions, which suggests that they are related to the strong organic and halides excess in the precursor solution. The concurrent presence of the $\mathrm{PbI}_{2}$ peak at $2 \theta=29.7^{\circ}$ (ICSD code 24263) confirms that films do not form properly under these annealing conditions. On the other hand, temperatures higher than $120^{\circ} \mathrm{C}$ cause the appearance of $\mathrm{PbI}_{2}$ signatures together with a significant reduction of the perovskite XRD peaks amplitude, which means that perovskite decomposition is relevant. When temperature is fixed at $120^{\circ} \mathrm{C}$, highly oriented pure phase

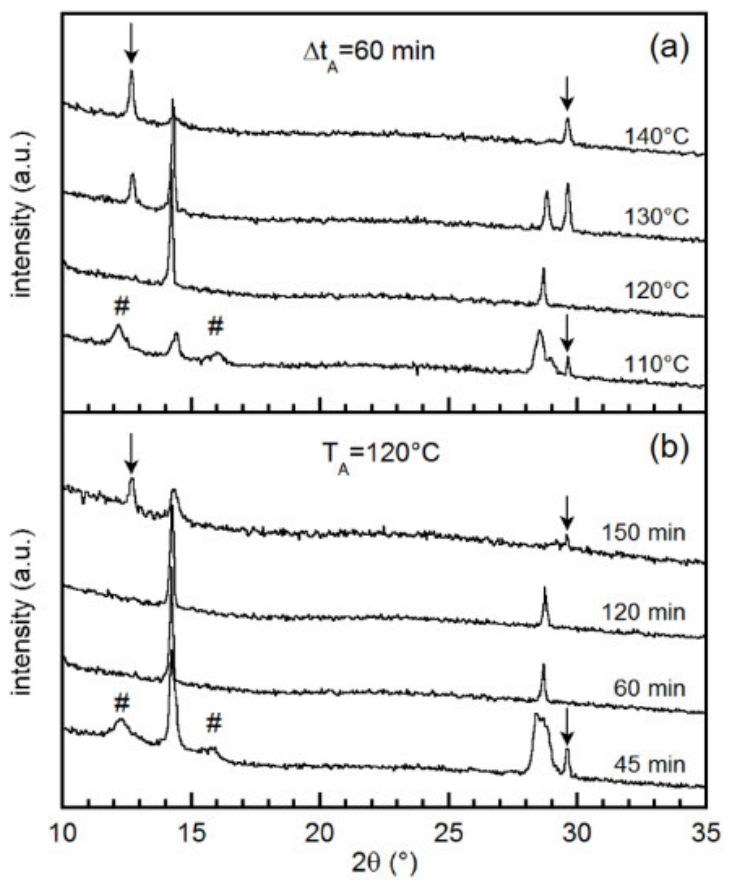

Figure 11 XRD patterns of perovskite films obtained from the 3:1 solution and treated for different (a) temperatures and (b) times, as indicated. Down arrows indicate the $\mathrm{PbI}_{2}$ peaks, whereas hashes point out the intermediate products.

perovskite films are achieved for times ranging from 60 to $120 \mathrm{~min}$ (Figure 11b), while shorter treatments (45 $\mathrm{min}$ ) result in poorly formed perovskites and treatments as long as $150 \mathrm{~min}$ cause perovskite decomposition.

Diffuse reflectance measurements confirm that films treat at $\mathrm{T}_{\mathrm{A}}=110^{\circ} \mathrm{C}$ show in a low absorption efficiency that indicates that at this temperatures conversion to the final perovskite is only partial. Films treated at $120^{\circ} \mathrm{C}$ for 60 and $120 \mathrm{~min}$ give pure phase perovskite films (Figure 12), but longer durations or higher temperatures make a high $\mathrm{PbI}_{2}$ absorbance step appear at about $515 \mathrm{~nm}$, which points out that perovskite decomposition is strong and $\mathrm{PbI}_{2}$ is no more an impurity phase. Interestingly, varying the annealing conditions shifts the position of the absorbance onset (Figure 12) which indicates that composition changes. In particular, except for the lowest temperature $\left(110^{\circ} \mathrm{C}\right)$, bromide content increases significantly with annealing time and temperature (Table 1). Since the Urbach energy shows a similar trend, we conclude that both composition and disorder depend on the thermal treatment much more than in samples prepared by using the "1.2:1" solution. This is likely due to the highly non-stoichiometric nature of the 3:1 precursor solution since in this case perovskite formation requires not only solvent evaporation and perovskite crystallization, but also the loss of the large methylammonium halides excess 
that leads to intermediate spurious phases in the early stages of the film formation. Thus, perovskite formation follows from the balance among different concurrent and interacting processes, whose rates depend on the thermal cycle. In these conditions the necessary reproducibility can be guaranteed only by a very accurate control of the synthetic procedure, which makes this solution little attractive for solar cell fabrication.

Table $1 \mathrm{E}_{\mathrm{G}}, \mathrm{E}_{0}$ and $\mathrm{x}$ values for perovskites obtained from the 3:1 solution by different annealing temperatures and durations. Compositions were estimated by Eq.1 from the relevant $E_{G}$ values

\begin{tabular}{|c|c|c|c|}
\hline \multicolumn{5}{|c|}{ annealing time $=60 \mathrm{~min}$} \\
\hline $\mathrm{T}_{\mathrm{A}}\left({ }^{\circ} \mathrm{C}\right)$ & $\mathrm{E}_{\mathrm{G}}(\mathrm{eV})$ & $\mathrm{x}$ & $\mathrm{E}_{0}(\mathrm{meV})$ \\
\hline 110 & 1.96 & 1.70 & 300 \\
\hline 120 & 1.69 & 0.47 & 38 \\
\hline 130 & 1.75 & 0.76 & 84 \\
\hline 140 & 1.82 & 1.10 & 265 \\
\hline \multicolumn{4}{|c|}{ annealing temperature $=120^{\circ} \mathrm{C}$} \\
\hline$\Delta \mathrm{t}_{\mathrm{A}}(\mathrm{min})$ & $\mathrm{E}_{\mathrm{G}}(\mathrm{eV})$ & $\mathrm{x}$ & $\mathrm{E}_{0}(\mathrm{meV})$ \\
\hline 45 & 1.66 & 0.31 & 66 \\
\hline 60 & 1.69 & 0.47 & 38 \\
\hline 120 & 1.71 & 0.57 & 45 \\
\hline 150 & 1.86 & 1.28 & 173 \\
\hline
\end{tabular}

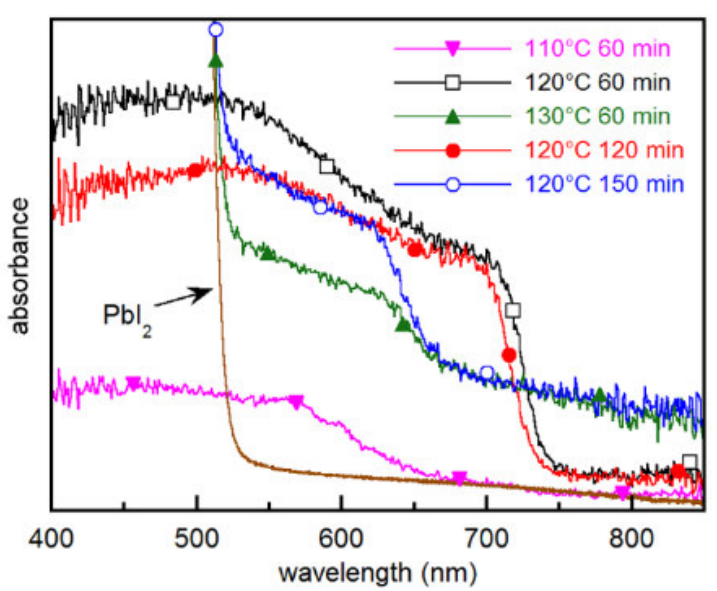

Figure 12 Absorbance spectra of perovskite films obtained from the $3: 1$ solution and treated for the indicated temperatures and times. A typical absorbance spectrum of a $\mathrm{PbI}_{2}$ film is also reported.

\section{Conclusions}

I-Br mixed-halide perovskites $\left(\mathrm{MAPbI}_{3-\mathrm{x}} \mathrm{Br}_{\mathrm{x}}\right)$ films have been prepared by single step solution processes fully performed in ambient air using different precursor solutions.

Tuning the $\mathrm{Br}$ content in mixtures of $\mathrm{MAPbI}_{3}$ and $\mathrm{MAPbBr}_{3}$ solutions and measuring the bandgap energy by the Tauc analysis of diffuse reflectance measurements allowed us to achieve an $\mathrm{E}_{\mathrm{G}}(\mathrm{x})$ relation that is expected not to depend on film properties other than composition, contrary to the one previously derived from the absorbance onset. PL measurements performed by $325 \mathrm{~nm}$ excitation pointed out the presence of recombination centers whose energy depth in the bandgap increases with $\mathrm{x}$. The observation that these centers are not detected in the tri-alides suggests that their formation involve the simultaneous presence of iodide and bromide. Disorder evaluated through the Urbach energy shows a dependence on x closely 
related to the grain-size domain, which suggests that in those materials the sub-bandgap absorption is due to defect states localized at the grain boundaries.

The influence of the annealing procedures was then studied for different precursor solution. Using the $\mathrm{I}_{3} / \mathrm{Br}_{3}$ mixture allowed the perovskites to form properly upon short treatments ( $5 \mathrm{~min}$ ), with degradation beginning for 20 min annealing. The precursor solution made of $\mathrm{MABr}$ and $\mathrm{PbI}_{2}$ in $\mathrm{DMF}$ gave $\mathrm{MAPbI}_{2} \mathrm{Br}$ (i.e. $\mathrm{x}=1$ ), even if annealing in air required a slight $\mathrm{MABr}$ excess to compensate losses of the organic material during the thermal treatment. In this case, composition and Urbach energy were nearly independent of annealing temperature and duration, thus showing that $\mathrm{MAPb}_{2} \mathrm{Br}$ perovskite made using the 1.2:1 solution is compositionally more stable than its counterpart obtained by the $\mathrm{I}_{3} / \mathrm{Br}_{3}$ mixture. However, the small PL emission intensity of samples prepared in air from the 1.2:1 solution means that non-radiative recombination paths form, which may be an issue for high efficiency solar cell.

Finally, the precursor solution made of MAI and $\mathrm{PbBr}_{2}$ (3:1 molar ratio) in DMF required thermal treatments longer and performed at higher temperatures than the other solutions due to the large excess of halides and methylammonium ions that must be lost during the baking. In this case, perovskite composition and disorder depend strongly on the annealing parameters, so that the strict control of the annealing procedures was necessary to guarantee an acceptable reproducibility of the synthetic process, which makes this last solution the less suitable for solar cell production.

\section{Acknowledgements}

This work was partially supported by the MIST ER Consortium.

\section{References}

(1) Kim, H.-S.; Lee, C.-R.; Im, J.-H.; Lee, K.-B.; Moehl, T.; Marchioro, A.; Moon, S.-J.; Humphry-Baker, R.; Yum, J.-H.; Moser, J. E.; et al. Lead Iodide Perovskite Sensitized All-Solid-State Submicron Thin Film Mesoscopic Solar Cell with Efficiency Exceeding 9\%. Sci. Rep. 2012, 2, 591.

(2) Im, J.-H.; Lee, C.-R.; Lee, J.-W.; Park, S.-W.; Park, N.-G. 6.5\% Efficient Perovskite Quantum-DotSensitized Solar Cell. Nanoscale 2011, 3, 4088.

(3) Ball, J. M.; Lee, M. M.; Hey, A.; Snaith, H. J. Low-Temperature Processed Meso-Superstructured to Thin-Film Perovskite Solar Cells. Energy Environ. Sci. 2013, 6, 1739.

(4) Noh, J. H.; Im, S. H.; Heo, J. H.; Mandal, T. N.; Seok, S. Il. Chemical Management for Colorful, Efficient, and Stable Inorganic-Organic Hybrid Nanostructured Solar Cells. Nano Lett. 2013, 13, 17641769. 
(5) Jeon, N. J.; Noh, J. H.; Kim, Y. C.; Yang, W. S.; Ryu, S.; Seok, S. Il. Solvent Engineering for HighPerformance Inorganic-Organic Hybrid Perovskite Solar Cells. Nat. Mater. 2014, 13, 897-903.

(6) Bi, C.; Yuan, Y.; Fang, Y.; Huang, J. Low-Temperature Fabrication of Efficient Wide-Bandgap Organolead Trihalide Perovskite Solar Cells. Adv. Energy Mater. 2014, 5, 1401616.

(7) Park, N.-G. Perovskite Solar Cells: An Emerging Photovoltaic Technology. Mater. Today 2014, 18, 6572.

(8) Jung, H. S.; Park, N.-G. Perovskite Solar Cells: From Materials to Devices. Small 2015, 11, 10-25.

(9) Gao, P.; Gratzel, M.; Nazeeruddin, M. K. Organohalide Lead Perovskites for Photovoltaic Applications. Energy Environ. Sci. 2014, 7, 2448-2463.

(10) Kim, H. S.; Im, S. H.; Park, N. Organolead Halide Perovskite : New Horizons in Solar Cell Research Organolead Halide Perovskite : New Horizons in Solar Cell. J. Phys. Chem. Lett. 2014, 118, 5615-5625.

(11) Salim, T.; Sun, S.; Abe, Y.; Krishna, A.; Grimsdale, A. C.; Lam, Y. M. Perovskite-Based Solar Cells: Impact of Morphology and Device Architecture on Device Performance. J. Mater. Chem. A 2015, 3, 8943-8969.

(12) Luo, S.; Daoud, W. A. Recent Progress in Organic-inorganic Halide Perovskite Solar Cells: Mechanisms and Material Design. J. Mater. Chem. A 2015, 3, 8992-9010.

(13) Eperon, G. E.; Burlakov, V. M.; Docampo, P.; Goriely, A.; Snaith, H. J. Morphological Control for High Performance, Solution-Processed Planar Heterojunction Perovskite Solar Cells. Adv. Funct. Mater. 2014, 24, 151-157.

(14) Dualeh, A.; Tétreault, N.; Moehl, T.; Gao, P.; Nazeeruddin, M. K.; Grätzel, M. Effect of Annealing Temperature on Film Morphology of Organic-Inorganic Hybrid Pervoskite Solid-State Solar Cells. Adv. Funct. Mater. 2014, 24, 3250-3258.

(15) Grancini, G.; Marras, S.; Prato, M.; Giannini, C.; Quarti, C.; Angelis, F. De; Bastiani, M. De; Eperon, G. E.; Snaith, H. J.; Manna, L.; et al. The Impact of the Crystallization Processes on the Structural and Optical Properties of Hybrid Perovskite Films for Photovoltaics. J. Phys. Chem. Lett. 2014, 5, 38363842.

(16) Yamada, Y.; Nakamura, T.; Endo, M.; Wakamiya, A.; Kanemitsu, Y. Near-Band-Edge Optical Responses of Solution-Processed Organic-inorganic Hybrid Perovskite CH3NH3PbI3 on Mesoporous TiO2 Electrodes. Appl. Phys. Express 2014, 7, 32302.

(17) Colella, S.; Mosconi, E.; Fedeli, P.; Listorti, A.; Orlandi, F.; Ferro, P.; Besagni, T.; Rizzo, A.; Calestani, G.; Gigli, G.; et al. MAPbI3-xClx Mixed Halide Perovskite for Hybrid Solar Cells : The Role of Chloride as Dopant on the Transport and Structural Properties. Chem. Mater. 2013, 25, 4613-4618.

(18) Chen, Q.; Zhou, H.; Fang, Y.; Stieg, A. Z.; Song, T.-B.; Wang, H.-H.; Xu, X.; Liu, Y.; Lu, S.; You, J.; et al. The Optoelectronic Role of Chlorine in CH3NH3PbI3(Cl)-Based Perovskite Solar Cells. Nat. Commun. 2015, 6, 7629 (1-9). 
(19) Qiu, J.; Qiu, Y.; Yan, K.; Zhong, M.; Mu, C.; Yan, H.; Yang, S. All-Solid-State Hybrid Solar Cells Based on a New Organometal Halide Perovskite Sensitizer and One-Dimensional TiO2 Nanowire Arrays. Nanoscale 2013, 5, 3245-3248.

(20) Yang, M.; Guo, R.; Kadel, K.; Liu, Y.; O’Shea, K.; Bone, R.; Wang, X.; He, J.; Li, W. Improved Charge Transport of Nb-Doped TiO2 Nanorods in Methylammonium Lead Iodide Bromide Perovskite Solar Cells. J. Mater. Chem. A 2014, 2, 19616-19622.

(21) Baikie, T.; Fang, Y.; Kadro, J. M.; Schreyer, M.; Wei, F.; Mhaisalkar, S. G.; Gratzel, M.; White, T. J. Synthesis and Crystal Chemistry of the Hybrid Perovskite (CH3NH3)PbI3 for Solid-State Sensitised Solar Cell Applications. J. Mater. Chem. A 2013, 1, 5628-5641.

(22) You, J.; Yang, Y. (Michael); Hong, Z.; Song, T.-B.; Meng, L.; Liu, Y.; Jiang, C.; Zhou, H.; Chang, W.H.; Li, G.; et al. Moisture Assisted Perovskite Film Growth for High Performance Solar Cells. Appl. Phys. Lett. 2014, 105, 183902.

(23) Bass, K. K.; McAnally, R. E.; Zhou, S.; Djurovich, P. I.; Thompson, M. E.; Melot, B. C. Influence of Moisture on the Preparation, Crystal Structure, and Photophysical Properties of Organohalide Perovskites. Chem. Commun. 2014, 50, 15819-15822.

(24) Pathak, S.; Sepe, A.; Sadhanala, A.; Deschler, F.; Haghighirad, A.; Sakai, N.; Goedel, K. C.; Stranks, S. D.; Noel, N.; Price, M.; et al. Atmospheric Infl Uence upon Crystallization and Electronic Disorder and Its Impact on the Photophysical Properties of Organic-Inorganic Perovskite Solar Cells. ACS Nano 2015, 9, 2311-2320.

(25) Zhou, H.; Chen, Q.; Li, G.; Luo, S.; Song, T.-B.; Duan, H.-S.; Hong, Z.; You, J.; Liu, Y.; Yang, Y. Interface Engineering of Highly Efficient Perovskite Solar Cells. Science. 2014, 345, 542-546.

(26) Kojima, A.; Teshima, K.; Shirai, Y.; Miyasaka, T. Organo Metal Halide Perovskites as Visible-Light Sensitizer for Photovoltaic Cells. J. Am. Chem. Soc. 2009, 131, 6050-6051.

(27) Lee, M. M.; Teuscher, J.; Miyasaka, T.; Murakami, T. N.; Snaith, H. J. Efficient Hybrid Solar Cells Based on Meso-Superstructured Organometal Halide Perovskites. Science. 2012, 338, 643-647.

(28) Kubelka, P. New Contributions to the Optics of Intensely Light-Scattering Materials. J. Opt. Soc. Am. 1948, 38 (5), 448-457.

(29) Wendlandt, W.; Hecht, H. C. Reflectance Spectroscopy; Wiley Interscience: New York, 1966.

(30) Kulkarni, S. A.; Baikie, T.; Boix, P. P.; Yantara, N.; Mathews, N.; Mhaisalkar, S. Band-Gap Tuning of Lead Halide Perovskites Using a Sequential Deposition Process. J. Mater. Chem. A 2014, 2, 9221-9225.

(31) Murphy, A. B. Band-Gap Determination from Diffuse Reflectance Measurements of Semiconductor Films, and Application to Photoelectrochemical Water-Splitting. Sol. Energy Mater. Sol. Cells 2007, 91, $1326-1337$.

(32) Boldish, S. I.; White, W. B. Optical Band Gaps of Selected Ternary Sulfide Minerals. Am. Mineral. 1998, $83,865-871$.

Tauc, J. Amorphous and Liquid Semiconductors; Plenum: London, 1974. 
(34) Sadhanala, A.; Deschler, F.; Thomas, T. H.; Dutton, S. E.; Goedel, K. C.; Hanusch, F. C.; Lai, M. L.; Steiner, U.; Bein, T.; Docampo, P.; et al. Preparation of Single Phase Films of CH3NH3Pb(I1-xBrx)3 with Sharp Optical Band Edges. J. Phys. Chem. Lett. 2014, 5, 2501-2505.

(35) Van Vechten, J.; Bergstresser, T. Electronic Structures of Semiconductor Alloys. Phys. Rev. B 1970, 1, 3351-3358.

(36) Edri, E.; Kirmayer, S.; Cahen, D.; Hodes, G. High Open-Circuit Voltage Solar Cells Based on Organic Inorganic Lead Bromide Perovskite. J. Phys. Chem. Lett. 2013, 4, 897-902.

(37) Urbach, F. The Long-Wavelength Edge of Photographic Sensitivity and of the Electronic Absorption of Solids. Phys. Rev. 1953, 92, 1324.

(38) Cody, G. D.; Tiedje, T.; Abeles, B.; Brooks, B.; Goldstein, Y. Disorder and the Optical-Absorption Edge of Hydrogenated Amorphous Silicon. Phys. Rev. Lett. 1981, 47, 1480-1483.

(39) Shen, W. Z.; Jiang, L. F.; Yang, H. F.; Meng, F. Y.; Ogawa, H.; Guo, Q. X. Bandtail Characteristics in InN Thin Films. Appl. Phys. Lett. 2002, 80, 2063-2065.

(40) De Wolf, S.; Holovsky, J.; Moon, S. J.; Löper, P.; Niesen, B.; Ledinsky, M.; Haug, F. J.; Yum, J. H.; Ballif, C. Organometallic Halide Perovskites: Sharp Optical Absorption Edge and Its Relation to Photovoltaic Performance. J. Phys. Chem. Lett. 2014, 5, 1035-1039.

(41) Kim, Y.-H.; Cho, H.; Heo, J. H.; Kim, T.-S.; Myoung, N.; Lee, C.-L.; Im, S. H.; Lee, T.-W. Multicolored Organic/Inorganic Hybrid Perovskite Light-Emitting Diodes. Adv. Mater. 2015, 27, 1248-1254.

(42) Burschka, J.; Pellet, N.; Moon, S.-J.; Humphry-Baker, R.; Gao, P.; Nazeeruddin, M. K.; Grätzel, M. Sequential Deposition as a Route to High-Performance Perovskite-Sensitized Solar Cells. Nature 2013, 499, 316-319.

(43) Zhang, W.; Saliba, M.; Moore, D. T.; Pathak, S.; Horantner, M.; Stergiopoulos, T.; Stranks, S. D.; Eperon, G. E.; Alexander-Webber, J. a; Abate, A.; et al. Ultra-Smooth Organic-Inorganic Perovskite Thin-Film Formation and Crystallization for Efficient Planar Heterojunction Solar Cells. Nat. Commun. 2014, 6, 6142 .

(44) Kim, H.-B.; Choi, H.; Jeong, J.; Kim, S.; Walker, B.; Song, S.; Kim, J. Y. Mixed Solvents for the Optimization of Morphology in Solution-Processed, Inverted-Type Perovskite/fullerene Hybrid Solar Cells. Nanoscale 2014, 6, 6679-6683.

(45) Xiao, Z.; Dong, Q.; Bi, C.; Shao, Y.; Yuan, Y.; Huang, J. Solvent Annealing of Perovskite-Induced Crystal Growth for Photovoltaic-Device Efficiency Enhancement. Adv. Mater. 2014, 26, 6503-6509.

(46) Etgar, L.; Gao, P.; Xue, Z.; Peng, Q.; Chandiran, A. K.; Liu, B. Mesoscopic CH3NH3PbI3/TiO2 Heterojunction Solar Cells. J. Am. Chem. Soc. 2012, 134, 17396-17399.

(47) Zhang, M.; Lyu, M.; Yu, H.; Yun, J.-H.; Wang, Q.; Wang, L. Stable and Low-Cost Mesoscopic CH3NH3PbI2Br Perovskite Solar Cells by Using a Thin Poly(3-Hexylthiophene) Layer as a Hole Transporter. Chem. Eur. J. 2015, 21, 434-439.

(48) Zhao, Y.; Zhu, K. Efficient Planar Perovskite Solar Cells Based on 1.8 eV Band Gap CH3NH3PbI2Br Nanosheets via Thermal Decomposition. J. Am. Chem. Soc. 2014, 136, 12241-12244. 
(49) Chen, Q.; Zhou, H.; Song, T.; Luo, S.; Hong, Z. Controllable Self-Induced Passivation of Hybrid Lead Iodide Perovskites toward High Performance Solar Cells. Nano Lett. 2014, 14, 4158-4163.

(50) Zhao, Y.; Zhu, K. CH3NH3Cl-Assisted One-Step Solution Growth of CH3NH3PbI3 : Structure, ChargeCarrier Dynamics, and Photovoltaic Properties of Perovskite Solar Cells. J. Phys. Chem. C 2014, 118, 9412-9418. 
TOC image

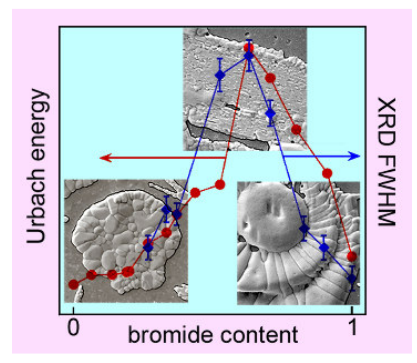

